\title{
Histopathological Evaluation of Lymph Node Biopsies: A Hospital Based Study
}

\author{
Md. Atiqur Rahman ${ }^{1}$, Md. Mamun Ali Biswas ${ }^{2}$, Syeda Tasfia Siddika ${ }^{3}$, Abdul Mannan Sikder ${ }^{4}$
}

\begin{abstract}
Background: Lymphadenopathy is a common manifestation of a large variety of disorders, both benign and malignant. It is essential to define the pattern of disorders presenting primarily as lymph node enlargement in a particular environment. Histopathological examination of the lymph node biopsies is a gold standard test in the distinction between reactive and malignant lymphoid proliferations as well as for detailed subtyping of lymphomas. We designed this study in our population for histopathological evaluation of lymph nodes that might be helpful for clinical management of these lesions. Objective: Histopathological evaluation of lymphadenopathy from excised specimen, in relation to age and sex of the patients, and distribution of the lymph nodes. Materials and Methods: It was a retrospective cross sectional study conducted in the department of Pathology, Enam Medical College \& Hospital, Savar, Dhaka during the period from January 2006 to December 2010. Lymph node biopsies of all patients of both sexes and all age groups were included. Metastatic lymph nodes associated with evidence of primaries elsewhere in the body were excluded from the study. Total 191 lymph node biopsies were selected for histopathological evaluation. Among these 90 (47.12\%) were from males and 101 (52.88\%) were from females with male to female ratio being 1:2.1. The age of the patients ranged from 2 to 85 years with a mean age of $35.73 \pm 18$ years. Results: Cervical lymph nodes were the most common (56\%) biopsied group. Of the 191 cases 59 cases (30.89\%) were reactive lymphadenitis, 64 cases (33.5\%) were tuberculosis, 2 cases (1.05\%) were non-caseous granuloma, 11 cases $(5.76 \%)$ were Hodgkin lymphoma, 22 cases (11.52\%) were non-Hodgkin lymphoma, 24 cases (12.57\%) were metastatic neoplasm and 9 cases (4.7\%) were other lesions. Conclusion: Tuberculosis was the most common cause of lymphadenopathy, followed by reactive lymphadenitis and the cervical group of lymph nodes was most frequently affected.
\end{abstract}

Keywords: Tuberculosis, Hodgkin lymphoma, Non-Hodgkin lymphoma, Metastatic neoplasm

J Enam Med Col 2012; 2(1):8-14

\section{Introduction}

Lymph nodes are discrete ovoid lymphoid structures that are widely distributed throughout the body. Lymphadenopathy refers to nodes that are abnormal in size, consistency or number, caused by the invasion or propagation of either inflammatory cells or neoplastic cells into the nodes.

Clinically, lymphadenopathy may be peripheral or visceral. Peripheral lymphadenopathies are easily

1. Associate Professor, Department of Pathology, Enam Medical College, Savar, Dhaka

2. Assistant Professor, Department of Pathology, Enam Medical College, Savar, Dhaka

3. OSD, DGHS, Mohakhali, Dhaka

4. Professor, Department of Pathology, Enam Medical College, Savar, Dhaka

Correspondence: Md.Atiqur Rahman,E-mail: mdatiq07@gmail.com 
detected by routine physical examination and are often biopsied as they are easily accessible for lymphadenectomy, which is a minor surgical procedure. Visceral lymphadenopathy on the other hand, requires laparotomy or sophisticated imaging techniques for detection.

Among the peripheral nodes, those in the upper part of the body (cervical, supraclavicular, axillary) are preferentially biopsied than lower limb nodes (popliteal, inguinal or femoral) as the former are more likely to yield definitive diagnosis whereas the latter are often characterized by non-specific reactive or chronic inflammatory and fibrotic changes. ${ }^{1,2}$

Lymphadenopathy is a common clinical problem, and biopsies are usually undertaken to determine the cause of nodal enlargement. Various reports document tuberculosis and infectious etiology as major causes of lymph node enlargement, ${ }^{3,4}$ whereas malignancies as a predominant cause in the developed countries. ${ }^{5,6}$ Increase in incidence of tuberculosis attributed to the advent and preponderance of HIV infection has been documented worldwide. ${ }^{7,8,9}$

Considering the plethora of diseases that may cause lymphadenopathy, it is essential to define the pattern of disorders presenting primarily as lymph node enlargement in a particular environment. ${ }^{10}$ Pattern of lymph node enlargement is different in different age group. Metastatic deposit is common in adults whereas it is rare in children. ${ }^{11,12}$ Reactive hyperplasia to minor stimuli has been reported as a significant cause of lymphadenopathy in children. ${ }^{13}$

The intent of this study was etiological evaluation of lymphadenopathy, in relation to age and sex of the patients and pattern of lymph node distribution in lymph node biopsy samples received in the department of Pathology, Enam Medical College \& Hospital.

\section{Materials and Methods}

This is a retrospective cross sectional study of lymph node biopsies conducted in the department of Pathology of Enam Medical College \& Hospital, Savar, Dhaka during a period of 5 years, from January 2006 to December 2010. A total of 191 lymph node biopsies were selected for histopathological evaluation. Histology slides of all cases were reviewed and clinicodemographic data regarding age, sex, anatomical site of nodal biopsy and clinical information were obtained from histology request forms and register. All biopsies were fixed in $10 \%$ formalin and routine hematoxylene-eosin stained sections were examined. Special stains like Ziehl-Neelsen and Periodic AcidSchiff stains were employed where necessary.

Lymph node biopsies (e.g., cervical, axillary, inguinal, abdominal) of all patients of both sexes and all age groups were included. Metastatic lymph nodes associated with evidence of primaries elsewhere in the body, e.g., axillary nodes in breast carcinoma or lymph nodes sent as part of main specimen such as surgery of bowel and gall bladder were not included in this study. Only one biopsy per patient was included. Results were interpreted in respect of age, sex and site of lymphadenopathy on the basis of histopathological diagnosis.

Non-Hodgkin lymphomas (NHLs) were classified based on working formulation. Diagnosis of tuberculosis was confirmed by demonstration of epithelioid granuloma with caseation necrosis on histopathological examination. The results were tabulated and presented as percentage frequencies. Means and standard deviations (SD) were used to summarize continuous variables, while percentages were used for categorical variables.

\section{Results}

A total of 191 lymph node specimens were received in the department of Pathology, Enam Medical College \& Hospital, Savar, Dhaka from 2006 to 2010 , accounting for $4 \%$ of all surgical biopsy specimens examined. There were $90(47.12 \%)$ males and $101(52.88 \%)$ females with male to female ratio being 1:2.1. The age of the patients ranged from 2 to 85 years with a mean age of $35.73 \pm 18$ years. The mean age of male patients was $35.44 \pm 20.73$ years and that of the female patients was $35.79 \pm 15.28$ years. Most of the patients were in the $3^{\text {rd }}$ decade (22\%) followed by $4^{\text {th }}$ decade (17.8\%) of life (Fig 1). Amongst males, maximum number of cases (16.7\%) were in $4^{\text {th }}$ decade, while amongst females, maximum number of cases $(28.7 \%)$ were in the $3^{\text {rd }}$ decade of life. 


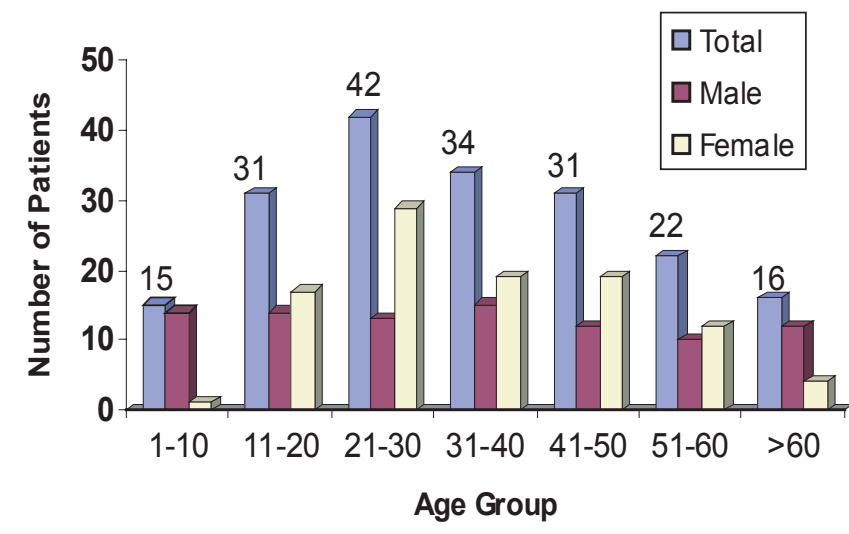

Cervical lymph nodes were the most commonly biopsied group (56\%), followed by axillary, abdominal and inguinal group of lymph nodes (Table I). The overall diagnostic yield in 191 biopsies was $64.4 \%$ with abdominal lymph nodes giving the highest yield $(67.9 \%)$ and the submental group giving the least diagnostic yield. Among the different spectrum of lesions, $65.2 \%$ cases of $\mathrm{TB}, 57.6 \%$ of reactive lesions, $42.4 \%$ of lymphoma, $50 \%$ of metastatic neoplasms and $44.4 \%$ of other specific causes of lymphadenitis were found in the cervical group of lymph nodes.

Fig 1. Age and sex distribution of the patients

Table I: Distribution of various histopathologic diagnoses according to lymph node location and diagnostic yield in each group

\begin{tabular}{|c|c|c|c|c|c|c|c|c|c|}
\hline \multirow{2}{*}{$\begin{array}{l}\text { Lymph node } \\
\text { location }\end{array}$} & \multirow{2}{*}{$\begin{array}{c}\text { Total } \\
\text { number } \\
(\%)\end{array}$} & \multirow[t]{2}{*}{ Reactive } & \multirow[t]{2}{*}{ TB } & \multirow{2}{*}{$\begin{array}{l}\text { Non caseous } \\
\text { granuloma }\end{array}$} & \multicolumn{2}{|c|}{ Lymphoma } & \multirow{2}{*}{$\begin{array}{c}\text { Metastatic } \\
\text { neoplasm }\end{array}$} & \multirow{2}{*}{$\begin{array}{l}\text { Other } \\
\text { lesions }\end{array}$} & \multirow{2}{*}{$\begin{array}{r}\text { Diagnostic } \\
\text { yield (\%) }\end{array}$} \\
\hline & & & & & $\overline{\mathrm{HL}}$ & NHL & & & \\
\hline Cervical & $107(56)$ & 34 & 41 & 2 & 6 & 8 & 12 & 4 & 64.5 \\
\hline Submental & $1(0.5)$ & & & & & & & 1 & 0 \\
\hline Submandibular & $5(2.6)$ & 3 & & & 1 & 1 & & & 40 \\
\hline Supraclavicular & $7(3.7)$ & 2 & 4 & & & & & 1 & 57.1 \\
\hline Axillary & $31(16.2)$ & 7 & 9 & & 2 & 5 & 5 & 3 & 67.7 \\
\hline Inguinal & $12(6.3)$ & 4 & 3 & & 2 & 2 & 1 & & 66.7 \\
\hline Abdominal & $28(14.7)$ & 9 & 7 & & & 6 & 6 & & 67.9 \\
\hline
\end{tabular}

$\mathrm{TB}=$ Tuberculosis; $\mathrm{HL}=$ Hodgkin lymphoma; $\mathrm{NHL}=$ Non-Hodgkin lymphoma

Diagnostic yield of each group is defined as: (Number of biopsies with specific histopathologic findings in this group/Total number of biopsies of the same group) $\times 100$

Distribution of various histological diagnoses, mean age values and sex distribution are shown in Table II. In this study, non-neoplastic lesions were more common comprising $70.16 \%$ (134 cases). TB was the most common cause of lymphadenopathy and accounts for $47.76 \%$ of all non-neoplastic lesions.
Females were more frequently affected compared to males with a female to male ratio of $1.78: 1$. Most of the patients $(\mathrm{n}=51 ; 79.7 \%)$ were between $11-40$ years of age (Table III). Caseous granuloma was found in all of these cases. Noncaseating granuloma was seen in only two biopsies.

Table II: Age and sex distribution of 191 patients with lymphadenopathy

\begin{tabular}{|c|c|c|c|c|c|c|}
\hline \multirow[t]{2}{*}{ Diagnosis } & \multirow[t]{2}{*}{ Total number (\%) } & \multicolumn{3}{|c|}{ Gender } & \multicolumn{2}{|c|}{ Age (Year) } \\
\hline & & Male & Female & $M: F$ & Range & Mean \pm SD \\
\hline Reactive & $59(30.89)$ & 29 & 30 & $1: 1.03$ & $2-80$ & $34.32 \pm 20.87$ \\
\hline TB & $64(33.5)$ & 23 & 41 & $1: 1.78$ & $10-75$ & $31.22 \pm 13.72$ \\
\hline Non-caseous granuloma & $2(1.05)$ & 1 & 1 & $1: 1$ & $19-38$ & $28.50 \pm 13.44$ \\
\hline $\mathrm{HL}$ & $11(5.76)$ & 10 & 1 & $10: 1$ & $30-85$ & $53.09 \pm 19.09$ \\
\hline NHL & $22(11.52)$ & 14 & 8 & $1.75: 1$ & $5-65$ & $36.23 \pm 19.02$ \\
\hline Metastatic neoplasm & $24(12.57)$ & 11 & 13 & $1: 1.2$ & $17-65$ & $46.04 \pm 12.44$ \\
\hline *Other lesions & $9(4.7)$ & 2 & 7 & $1: 3.5$ & $12-45$ & $26.56 \pm 13.09$ \\
\hline Total & 191 & 90 & 101 & $1: 2.11$ & $2-85$ & $35.73 \pm 18.00$ \\
\hline
\end{tabular}

*detailed in the text under Results 
Table III: Histological diagnosis and age of 191 patients with lymph node biopsies

\begin{tabular}{|c|c|c|c|c|c|c|c|}
\hline \multirow[t]{2}{*}{ Age } & \multicolumn{4}{|c|}{ Non-neoplastic lesion $(n=134 ; 70.16 \%)$} & \multicolumn{3}{|c|}{ Neoplastic lesion $(n=57 ; 29.8 \%)$} \\
\hline & Reactive & TB & $\begin{array}{l}\text { Non-caseous } \\
\text { granuloma }\end{array}$ & Other lesions & HL & NHL & $\begin{array}{l}\text { Metastatic } \\
\text { neoplasm }\end{array}$ \\
\hline $1-10$ & 11 & 2 & & & & 2 & \\
\hline $11-20$ & 5 & 16 & 1 & 4 & & 5 & 1 \\
\hline $21-30$ & 14 & 20 & & 2 & 2 & 2 & 2 \\
\hline $31-40$ & 6 & 17 & 1 & 1 & 2 & 2 & 6 \\
\hline $41-50$ & 10 & 5 & & 2 & 2 & 6 & 6 \\
\hline $51-60$ & 6 & 3 & & & 1 & 4 & 8 \\
\hline$>60$ & 7 & 3 & & & 4 & 1 & 1 \\
\hline Total & 59 & 64 & 2 & 9 & 11 & 22 & 24 \\
\hline
\end{tabular}

Reactive lymphadenitis was the second most common cause of lymphadenopathy and accounts for $44 \%$ of all non-neoplastic lesions. Out of 59 cases, $30(50.8 \%)$ were follicular hyperplasia, 19 (32.2\%) were sinus histiocytosis and $10(16.9 \%)$ were chronic non-specific lymphadenitis.

Malignancies comprised $29.8 \%$ (57 cases) of enlarged lymph node with lymphomas predominating accounting for $17.3 \%$, making them collectively the third most prevalent cause of lymphadenopathy in this series. Among the lymphomas, non-Hodgkin lymphomas (NHLs) were more common with intermediate and high grade types being predominant (Table IV). Hodgkin lymphoma was predominantly observed in males (Table II). Mixed cellularity type was the most common subtype, seen in 7 cases $(63.6 \%)$, followed by lymphocyte predominance and nodular sclerosis types (Table IV).

Metastatic neoplasm accounts for $42.1 \%$ of malignant lesions. Among the various types of tumors metastasizing the lymph nodes, adenocarcinoma was the commonest comprising $37.5 \%$ (9 cases), followed by squamous cell carcinoma $(\mathrm{n}=6 ; 25 \%)$, breast cancer involvement of axillary nodes $(n=5 ; 20.8 \%)$, poorly differentiated carcinoma $(n=2$; $8.3 \%)$, papillary carcinoma of the thyroid gland $(n=1 ; 4.2 \%)$ and nasopharyngeal carcinoma $(\mathrm{n}=1 ; 4.2 \%)$.

Table IV: Nodal lymphomas in 33 patients

$\begin{array}{lc}\text { Morphologic types } & \text { No of cases (\% for group) } \\ \text { Non-Hodgkin lymphoma } & \\ \quad \text { Low grade } & 2(9.2) \\ \text { Intermediate grade } & 14(63.6) \\ \text { High grade } & 6(27.2) \\ \quad \text { Total } & 22(100) \\ \text { Hodgkin lymphoma } & \\ \text { Nodular sclerosis } & 1(9.1) \\ \text { Mixed cellularity } & 7(63.6) \\ \text { Lymphocyte predominance } & 3(27.3) \\ \text { Lymphocyte-rich } & - \\ \text { Lymphocyte depletion } & - \\ \text { Total } & 11(100)\end{array}$

Other patterns of lymphadenopathies were identified in 9 cases $(4.7 \%)$ comprising of 5 cases of acute lymphadenitis, 3 cases of Kikuchi's necrotizing lymphadenitis and 1 case of necrotic foci with neutrophils suggestive of cat-scratch disease (Table II).

\section{Discussion}

Patients presenting with enlargement of the lymph nodes is one of the most common problems in clinical practice. ${ }^{14}$ Lymphadenopathy offers an important diagnostic clue to the etiology of the underlying condition. The cause of lymphadenopathy often cannot be ascertained on clinical grounds alone. Excision biopsy of the lymph node provides material to establish an early diagnosis and is a vital part of the management. ${ }^{15}$

In this study, cervical lymph nodes were the most frequently biopsied constituting $56 \%$ of nodal biopsies. This is consistent with virtually all other lymph node studies. ${ }^{15,16}$ Next common group includes axillary and abdominal lymph node biopsies which comprised $14.7 \%$ and $14.13 \%$ respectively. The overall diagnostic yield of lymph node biopsy was $64.4 \%$. A study done by Morad $\mathrm{N}$ et $\mathrm{al}^{17}$ revealed diagnostic yield of $67 \%$ with supraclavicular lymph nodes giving the highest yield of $80 \%$. In our study highest diagnostic yield $(67.9 \%)$ was found with abdominal lymph nodes and supraclavicular lymph nodes gave $57.1 \%$ yield.

In agreement with other studies benign lesions were more frequent comprising $70.2 \%$ of lymph node enlargement and malignant lesions constituted $29.8 \%{ }^{15,16}$ In contrast, a study 
done by Olu-Eddo AN et al ${ }^{10}$ revealed malignancy being the predominant lesion constituting $55 \%$ of cases. The higher incidence of malignant tumors are also documented in the western series. $5,6,18$

Tuberculosis was the commonest cause of lymphadenopathy in this study accounting for $33.5 \%$. Tuberculosis has also been reported by several authors as the predominant lesion in adults in the tropics. ${ }^{3,4}$ The studies performed in other developing countries also showed TB lymphadenitis being the most common cause of lymphadenopathy. ${ }^{16,19,20}$ The high incidence of TB has been attributed to the low socio-economic status and the attendant poor standard of living in the third world countries. $^{21}$

In the western countries, infections like TB have become rare and malignancies including lymphoma are the predominant causes of lymph node enlargement. ${ }^{5,6}$ The higher rates of tuberculosis in some African countries like Zambia is due to their higher HIV infection rates, tuberculosis being an AIDS-defining illness. ${ }^{8}$ Different other studies also revealed predominance of TB due to higher HIV infection. ${ }^{9}$ In the last three decades, HIV/AIDS has also been responsible for the resurgence of tuberculosis. Coincident with the AIDS epidemic, the incidence of tuberculosis has risen dramatically. Worldwide, almost a third of all deaths in AIDS patients are attributable to tuberculosis. Prior to the HIV pandemic, tuberculosis was declining due to improved living standards. ${ }^{7}$ We could not analyze the HIV status in patients with TB because test for HIV was not done.

In this study, TB affected mainly the cervical group of lymph nodes of young adult females with maximum at $21-30$ years and $80 \%$ of the patients were between $11-40$ years of age. Only $11 \%$ patients with TB lymphadenitis were above 40 years of age. These results are consistent with the findings of other authors. ${ }^{3,4,10,21}$ A study from Turkey showed that the most common site of extrapulmonary TB lymphadenitis was intrathoracic lymph nodes followed by cervical lymph nodes. ${ }^{22}$

Like Asian and North African populations, in the USA tubercular lymphadenitis was found to be more common in females as compared to males. ${ }^{23}$ Two cases of granulomas lacking caseation or other specific features were seen in this review. These possibly were early tuberculosis before the development of caseous necrosis. Both of these were negative for acid-fast bacilli (AFB).

Reactive lymphadenopathy was the second most common cause in this study and accounts for $30.89 \%$ of lymph node lesions. Out of 59 cases, $50.8 \%$ were follicular hyperplasia, $32.2 \%$ sinus histiocytosis and $16.9 \%$ chronic non-specific lymphadenitis. This is similar to the findings of Kamat $\mathrm{GC}^{20}$ where reactive lymphadenitis was also the second common cause of lymphadenitis next to TB $(30.73 \%$ and $58.19 \%$ respectively). This included 75 cases of reactive lymph nodes, $69.3 \%$ were follicular hyperplasia, $21.4 \%$ sinus histiocytosis, and 9.3\% paracortical hyperplasia. These results differ from that of Attah $\mathrm{EB}^{24}$, Sibanda et $\mathrm{al}^{25}$ and Moore et $\mathrm{al}^{26}$ who found reactive change highest followed by TB. Attah EB reported 33\% of reactive change and 30\% of TB, Sibanda et al found $33 \%$ of reactive change and $26.7 \%$ of TB and Moore et al found $47.8 \%$ of reactive lesions and $36.3 \%$ cases of TB.

Malignant tumors constituted $29.8 \%$ cases with lymphoma accounting for $17.3 \%$, making them collectively the third commonest cause of lymphadenopathy. These are consistent with the findings of other authors. ${ }^{10,17,18}$ However, some other authors found predominance of metastatic neoplasms among the malignancies. ${ }^{15,20}$ Among the lymphomas, NHLs were more common comprising $11.5 \%$ of lymphadenopathies while HL constituted $5.76 \%$. Other studies also document a preponderance of NHL over HL. ${ }^{10,15}$ In the western world NHL is reported to be three to four times more common than HL. The much higher proportion of NHL in the western world may be partly explained by racial and genetic factors. ${ }^{27}$

Intermediate and low grade lymphomas accounted for over $80 \%$ NHL in the USA ${ }^{27}$, whereas high and intermediate grades were predominant in our study comprising $91 \%$. In contrast to these studies, Naseem SS et al ${ }^{19}$ found predominance of HL over NHL ( 72 cases versus 27 cases).

Hodgkin lymphoma showed marked predilection for the cervical group of lymph nodes with a striking male to female ratio of 10:1. These findings corroborate with other findings. ${ }^{4,10}$ The mixed 
cellularity type is the most common pattern in the current study, in agreement with other studies. ${ }^{17,19}$

In the present study, metastatic tumors was the fourth commonest cause of lymphadenopathy constituting $12.57 \%$ cases, which is similar to the study of Shrestha AK et al. ${ }^{16}$ In agreement with others, majority of the patients $(62.5 \%)$ were above the age of 45 years. ${ }^{4,16}$ Out of 24 metastatic lesions, adenocarcinoma and squamous cell carcinomas were common comprising $37.5 \%$ and $25 \%$ respectively. The distribution of metastatic lymph nodes among both sexes depends upon the tumor type (primary), as metastatic lymph nodes in patients with breast carcinoma will be seen more in female patients and vice versa. $^{13}$

The varied etiology of lymphadenopathy observed at our tertiary care center, as documented by histopathological evaluation, was comparable to studies conducted in other developing countries. TB was the most common cause of lymphadenopathy, followed by reactive lymphadenitis and presented mostly with cervical lymphadenopathy. Females were frequently affected by $\mathrm{TB}$ as compared to males. In both HLs and NHLs males were frequently affected than females. Among the HLs, mixed cellularity was the commonest subtype and among the NHLs, intermediate grade lymphomas were more common. Among metastatic tumors, adenocarcinoma and squamous cell carcinoma were frequent.

\section{References}

1. Rosai J. Lymph nodes. In: Rosai and Ackerman's Surgical Pathology. $9^{\text {th }}$ edn. St. Louis: Elsevier Mosby, 2004: 1878-1888.

2. Ferrer R. Lymphadenopathy: differential diagnosis and evaluation. Am Fam Physician 1998; 58(6): 1313-1320.

3. Obafunwa JO, Olomu IN, Onyia NJ. Primary peripheral lymphadenopathy in Jos, Nigeria. West Afr J Med 1992; 11(1): 25-28.

4. Thomas JO, Ladipo JK, Yawe T. Histopathology of lymphadenopathy in a tropical country. East Afr Med J 1995; 72(11): 703-705.

5. Freidig EE, McClure SP, Wilson WR, Banks PM, Washington JA. Clinical-histologic-microbiologic analysis of 419 lymph node biopsy specimens. Clin Infect Dis 1986; 8(3): 322-328.

6. Sriwatanawongsa V, Cardoso R, Chang P. Incidence of malignancy in peripheral lymph node biopsy. Am Surg 1985; 51(10): 587-590.

7. Robbins S, Cotran R. Diseases of the immune system. In: Kumar V, Abbas AK, Sausto N, Aster JC (eds). Robbins and Cotran pathologic basis of disease. $8^{\text {th }}$ edn. Philadelphia: Elsevier Saunders, 2010: 235-249.

8. Bem C, Patil PS, Bharucha H, Namaambo K, Luo N. Importance of human immunodeficiency virusassociated lymphadenopathy and tuberculous lymphadenitis in patients undergoing lymph node biopsy in Zambia. Br J Surg 1996; 83(1): 75-78.

9. Chakraborty AK. Epidemiology of tuberculosis: current status in India. Indian J Med Res 2004; 120: 248-276.

10. Olu-Eddo AN, Ohanaka CE. Peripheral lymphadenopathy in Nigerian adults. J Pak Med Assoc 2006; 56(9): 405-408.

11. Okolo SN, Nwana EJ, Mohammed AZ. Histopathologic diagnoses of lymphadenopathy in children in Jos, Nigeria. Niger Postgrad Med J 2003; 10(3): 165-167.

12. Lake AM, Oski FA. Peripheral lymphadenopathy in childhood. Ten-year experience with excisional biopsy. Am J Dis Child 1978; 132(4): 357-359.

13. Adelusola KA, Oyelami AO, Odesanmi WO, Adeodu OO. Lymphadenopathy in Nigerian children. West Afr J Med 1996; 15: 97-100.

14. Leung AK, Robson WL. Childhood cervical lymphadenopathy. J Pediatr Health Care 2004; 18(1): 3-7.

15. Mohan A, Reddy MK, Phaneendra BV, Chandra A. Aetiology of peripheral lymphadenopathy in adults: analysis of 1724 cases seen at a tertiary care teaching hospital in Southern India. Natl Med J India 2007; 20(2): 78-80.

16. Shrestha AK, Chalise PR, Shrestha ML. Lymph node biopsies: a hospital based retrospective study. J Nepal Med Assoc 2009; 48(176): 306-309.

17. Morad N, Malatani T, Khan AR, Hussain N. Peripheral lymphadenopathy as a primary presenting sign: a study of 324 cases from Asir region. Annals of Saudi Medicine 1992; 12(1): 72-75.

18. Sinclair S, Beckman E, Ellman L. Biopsy of enlarged superficial lymph nodes. JAMA 1974; 228(5): 602-603.

19. Naseem SS, Nagi AH, Ashraf M, Bilal S, Akhlaq M, Henna N, Sami W. A pattern of lymphadenopathies seen in a tertiary care hospital in Lahore, Pakistan. Turk J Med Sci 2011; 41(2): 353-358.

20. Kamat GC. A ten-year histopathological study of generalized lymphadenopathy in India. S Afr Fam Pract 2011; 53(3): 267-270.

21. Narang P, Narang R, Mendiratta DK, Sharma SM, Tyagi 
NK. Prevalence of tuberculous lymphadenitis in children in Wardha district, Maharashtra State, India. Int J Tuberc Lung Dis 2005; 9(2): 188-194.

22. Ilgazli A, Boyaci H, Basyigit I, Yildiz F. Extrapulmonary tuberculosis: clinical and epidemiological spectrum of 636 cases. Arch Med Res 2004; 35(5): 435-441.

23. Cailhol J, Decludt B, Che D. Sociodemographic factors that contribute to the development of extrapulmonary tuberculosis were identified. J Clin Epidemiol 2005; 58(10): 1066-1071.
24. Attah EB. Peripheral lymphadenopathy in Nigeria. Trop Geogr Med 1974; 26(3): 257-260.

25. Sibanda EN, Stanczuk G. Lymph node pathology in Zimbabwe: a review of 2194 specimens. Q J Med 1993; 86(12): 811-817.

26. Moore SW, Schneider JW, Schaaf HS. Diagnostic aspects of cervical lymphadenopathy in children in the developing world: a study of 1877 surgical specimens. Pediatr Surg Int 2003; 19(4): 2040-2044.

27. Hartge P, Devessa SS, Fraumeni JF. Hodgkin's and nonHodgkin's lymphoma. Cancer Surv 1994; 19: 423-433. 